\title{
EL PASO DE UNA “DEMOCRACIA REPRESENTACIONISTA" A UNA "DEMOCRACIA PARTICIPATIVA" (CRISIS, FRACASO O REVITALIZACION DE LA DEMOCRACIA)
}

\author{
Dr. Roque Pozo*
}

Durante cuatro meses he quedado comprometido con la U.C.A., en calidad de profesor visitante, para impartir dos asignaturas que me han asignado. Los meses de marzo y abril, -a través de los medios de comunicación social y de frecuentes conversaciones con compañeros salvadoreños--, me han permitido seguir, no como mero observador, sino viviendo intensamente el acontecimiento electoral que, en principio, lo considero como un esfuerzo, -realizado desde distintas posiciones y actitudes políticas-, para recuperar sensibilidad y práctica democrática. Por éso, no he podido ni he querido permanecer al margen, aunque mi nacionalidad no sea salvadoreña y, por tanto, no haya ejercitado el derecho de votar. La democracia es una aspiración universalizable que, si uno es coherente, no puede ser indiferente ni inhibirse sea cual fuese el área geográfica en que se pretenda implantar, desarrollar y fortalecer.

Mi intención no es otra que la de intentar reflexionar, desde una actitud ético-crítica-constructiva, con el propósito de ayudar o contribuir a avanzar en mentalidad democratizadora, que cristali-

* Catedrático de la Universidad de Deusto (Profesor visitante en la UCA). 
ce en comportamientos personales y grupales del mismo signo y talante. En definitiva, poner, modestamente, un grano de arena en los cimientos de este edificio todavía poco sólido y poco consistente que es la democracia que, si somos rigurosos en el análisis, no nos será difícil caer en la cuenta de que, en unos países más y en otros menos, lo cierto es que, en todos, falta mucho camino por recorrer. Parafraseando la expresión machadiana, también en lo concerniente a la vida democrática "se hace camino al andar".

\section{Algunas consideraciones previas}

Permítaseme hacer algunas consideraciones previas que, al menos para mí, tienen el valor de afirmaciones. Son las siguientes:

- La democracia es un proceso siempre inacabado. Al igual que la sociedad lo es también, pues en ella la transformación y el cambio social son una constante histórico-sociológica y sus protagonistas se suceden en la medida que nuevas generaciones consolidan su protagonismo. También, en tanto personas, somos un proyecto inconcluso.

- Sin incurrir en falsa modestia, diré que, lejos de mí está la menor intencionalidad de dar lecciones de democracia a nadie, pues, sinceramente, a todo lo más que he llegado es a ser aprendiz impenitente de demócrata.

- Que en la sociedad en que vivimos es relativamente fácil detectar quiénes son las personas y cuáles son los grupos que se proponen y pueden, -siempre en términos relativos-, impulsar el proceso democrático; ó, por el contrario, oponen una determinada resistencia al mismo, toda vez que éste comporta cambios en la estructura social y sus posiciones de privilegio y de poder se pueden poner en cuestión.

- Que la democracia, para ser auténtica y no simple vacua retórica política, tiene que alejarse del individualismo destructivo y paralizante que nos atenaza y abrir vías de solidaridad constructivas y dinamizadoras. $Y$ ésto no será posible si no es capaz de implementar políticas económicas sociales y culturales que reduzcan las exageradas e insultantes diferencias entre ricos-privilegiados-opulentos y pobres-desposeídos-marginados. 
Es decir, que los ricos sean menos y menos ricos y los pobres sean igualmente menos y menos pobres.

- Que la democracia, que proclamaba y sigue proclamando igualdad, fraternidad y libertad, no renuncie a estos principios vitales y motivadores. $\mathrm{Y}$ que, si etimológica y políticamente, se define como gobierno del pueblo, con el pueblo, por el pueblo y para el pueblo, —de todo el pueblo-, no permita que el pueblo aparezca, en más ocasiones de las deseables y tolerables, como el gran ausente en lo relacionado con las decisiones que afectan a su vida y a sus intereses de todo tipo. Hoy, sin faltar a la verdad, ningún país, - a nada que examine su propia realidad con el fin de verla tal cual es-, podrá afirmar que en su sociedad, el pueblo que la constituye, es auténtico protagonista activo. Son muchos los hechos que demuestran la escasa o nula participación, cuando no la indiferencia popular. Las sociedades occidentales, pese a que, sin el menor reparo y sonrojo, se autodefinen como democráticas, son sociedades democráticamente enfermas. Me pregunto, ¿con sinceridad, podemos decir que existe hoy algún país o pueblo que se pueda presentar como modelo democrático a imitar? Mi respuesta, forzosamente ha de ser negativa, sin que tal apreciación signifique dejar de reconocer determinados avances democráticos que sería injusto no valorar en términos positivos.

\section{Unas primeras constataciones}

No podemos ignorar la, al menos relativa dificultad, que se presenta a la hora de hablar de democracia. Resumiendo mucho, la realidad histórica nos muestra dos experiencias: a) "democracia inorgánica", que se expresa a través de diferentes tendencias que, a su vez, se concretan en diversos partidos políticos - hoy proclives a la bipolarización-, con sus respectivas ideologías materializadas en programas de acción política que, en todo caso, se sustentan en cuadros dirigentes elegidos, en militantes afiliados-cotizantes y electorado-adicto que puede reconsiderar su adhesión; lo característico es la confrontación más o menos racional en comicios electorales que se realizan con una periodicidad preestablecida y constitucionalmente aceptada; y b) "democracia orgánica", basada en un partido político único, -vinculado en mayor o menor grado a 
un sindicato igualmente único-el cual actúa en la mayoría de los casos de forma incontrolada, autoritaria y prepotente; no propugna las libertades cívico-políticas y menos las reconoce y defiende, tendiendo a sustentarse en instituciones sociales (familia, municipios, sindicato y corporaciones profesionales) y a simular prácticas electorales que al no reflejar propuestas populares, concluyen en órganos políticos que se caracterizan por ser de asentimiento y aclamación más que de deliberación y confrontación, desembocando casi siempre en dictaduras amparadas en grupos de presión (poderes fácticos) de carácter económico, político y militar, habiéndose dado casos en los que el poder de instituciones eclesiásticas aparece - si no en su totalidad, al menos parcialmente- como adherido a los grupos de presión indicados.

Sé, o al menos así pienso, que los regímenes fundamentados en formas de "democracia orgánica", no se hallan absolutamente superados en todas partes y el riesgo o posibilidad de que puedan reaparecer no se puede reducir a mera suposición o hipótesis. No obstante, en este trabajo-reflexión sólo me centraré en las llamadas "democracias liberales inorgánicas" que, en el marco de formas de Estado monárquicas o republicanas, funcionan en el llamado ámbito occidental en el que nos hallamos situados. Más concretamente, a aquellos países que habiendo optado plebiscitariamente y promulgado su propia Constitución o Carta Magna: -reconocen, mantienen y defienden las libertades cívico-políticas de opinión, expresión, reunión, religión y asociación; -establecen la división de poderes - ejecutivo, legislativo y judicial一, propiciando que éste último actúe de manera independiente; -crean las cámaras parlamentarias necesarias para que se hagan presentes las distintas fuerzas políticas con la representación electoral alcanzada en las urnas; - reconocen y ejercitan el sufragio universal, - cada persona incluída en el censo electoral un voto-, y facilitan honestamente y con todos los medios posibles su práctica real;- promueven como institución básica el Tribunal de Garantías Constitucionales;y crean, asimismo, la institución fundamental del Defensor del Pueblo ante las posibles incorrecciones, abusos de poder e irregularidades en que puedan incurrir las administraciones públicas.

Esta es la democracia respecto de la cual, - parafraseando a W. Churchil-, podemos decir que es la "peor forma de gobierno,... 
excluyendo todas las demás". Es la democracia liberal instalada en el mundo occidental y que sirve como estructura de encuadramiento político al liberalismo económico concretado en el capitalismo liberal, individualista, tecnocratizado y consumista que, unos más otros menos, todos padecemos, en la medida que se aleja de dar respuesta eficaz y suficiente a necesidades individuales y sociales realmente sentidas y, por el contrario, con empecinamiento y sin freno crea necesidades artificiales, tal vez porque considera que la estupidez humana es inagotable y suceptible de manipulación "a gusto del consumidor".

No es casualidad que haya quienes, insultando a la inteligencia sin inmutarse, y sin rigor histórico, sociológico, analítico y estructural-dialéctico, elaboren opiniones pseudocientíficas en torno al "fin de las ideologías" y "al último hombre", dando por supuesto que la "ideología liberal" y "el especímen de ciudadano que genera" constituyen el último estadio alcanzado por la humanidad. Es fácil descubrir en estas tesis una intencionalidad desideologizadora, sin caer en la cuenta de que la desideologización es la peor de las ideologizaciones, toda vez que priva al ser humano de todo horizonte utópico y le empuja hacia el despeñadero de la deshumanización, impidiéndole algo tan radicalmente humano como es el pensar por sí mismo en solidaridad con todos sus semejantes. Igualmente, es fácil percibir que tras estas formulaciones se oculta una "ideología tecnocrática" pragmatista y productivista, antitética con lo que en rigor es una economía política racionalmente entendida y planteada.

¿Qué consecuencias se derivan de esta "ideología tecnocrática neoliberal"? Sencillamente, el individualismo del que somos tributarios y campa por sus respetos, dando lugar a un doble proceso: por un lado, con su carácter inmediatista y materialista, tiende a una autonomía absoluta del individuo respecto a cualquier planteamiento transcendente; $y$, por otro, propugna también la autonomía del individuo ante el grupo y la sociedad, abriendo de par en par las puertas a la insolidaridad e imposibilitando la consecución, humanamente hablando, del equilibrio deseable entre autoridad, responsabilidad y libertad. La consecuencia, asimismo, es que el Estado como ente jurídico-político al servicio de la sociedad, tampoco encuentra su verdadero sitio y se convierte - al menos 
relativamente- en instrumento de los grupos privilegiados y dominantes, que un "ver sociológico" puede identificar perfectamente.

\section{El sentido radical de la participación activa}

Tanto si nos referimos a la vida política como si lo hacemos a la vida económica y cultural estas realidades sólo podrán ser democráticas si hacen posible la participación activa en su sentido radical. Para explicar y entender esta proposición, consideraré la distinción entre la participación entendida como "formar parte de" y "tomar parte en".

En el primer caso, "formar parte de", el sujeto o los sujetos no son realmente partícipes, sino que se limitan a estar pasivamente. $\mathrm{Ni}$ piensan por sí mismos, ni cuestionan lo que otros piensan y proponen, quedando, por consiguiente, a la espera de lo que a éstos se les ocurra y hagan. Su participación queda reducida a la de simples espectadores que se limitan a asentir y se alejan de todo protagonismo y cuestionamiento crítico y autocrítico. Es tanto como aceptar la condición de minoría de edad de una manera permanente, negándose a aceptar la cuota parte de responsabilidad que hay en las decisiones que se toman. En el fondo, lo que subyace es un miedo a la libertad que, de hecho, es manipulado por quienes detentan posiciones de poder. Si sólo se "forma parte $\mathrm{de}^{\prime \prime}$, la realidad es que no se participa.

En cambio, en el segundo caso, que se expresa como "tomar parte en", sucede todo lo contrario. Quien toma parte, adquiere conciencia personal $-y$, en su caso, colectiva-, en el sentido de que se es protagonista y no espectador. Se piensa por sí mismo y se cuestiona y critica lo que se piensa, se dice y se hace y se ejercita al mismo tiempo en la sana práctica de la autocrítica. Es el signo de haber superado la fase infantil o de inmadurez y de haber entrado en la madurez o mayoría de edad real. Se adquiere entonces plena conciencia de la autonomía personal a la hora de pensar y discernir por sí mismo, asumiendo la parte de responsabilidad que dicho proceder conlleva. Así, "tomar parte en", se convierte en auténtica expresión de lo que es la participación activa.

Ahondando un poco más, diré que para que esta participación 
activa se dé en el cuádrupe plano - político, económico, social y cultural-, se tiene que registrar simultánea o sucesivamente en cuatro niveles, a saber: 1) informativo, que significa que toda persona es conveniente y puntualmente informada acerca de todos los hechos, fenómenos y situaciones que le afectan, respecto de los cuales tiene que elaborar su propia opinión, con la certidumbre de que ésta ha de ser escuchada; 2) consultivo, que supone que todos, individual o colectivamente, directamente o por representación, somos consultados antes de tomar decisiones que nos afectan, condicionan y limitan, al objeto de que, cuando aquéllas sean adoptadas, encuentren el máximo de consenso posible y así se reduzcan al mínimo o se eliminen los márgenes de instrumentación y manipulación que, de no hacerlo así, resultarían inevitables, y, en todo caso, la práctica sería negativa en el sentido de que, la opinión de quienes son considerados como "dirigidos" y "gobernados", no cuenta; 3) decisorio, que exige una presencia asamblearia o por representación en el momento de realizar opciones y tomar las decisiones que se estimen pertinentes, de forma que la decisión sea colectiva y la responsabilidad sea compartida y refleje un compromiso asumido por el mayor contingente posible de personas vinculadas a un proyecto en el que su forma de pensar, de sentir y de vivir están directamente implicadas; 4) de control, que posibilita un seguimiento y valoración de los proyectos que se ha decidido poner en marcha, al objeto de comprobar.si éstos se han realizado de la forma prevista y se han alcanzado los objetivos planteados, advirtiendo, asimismo, las desviaciones que se hayan producido $y$ las causas que las han originado.

Una participación activa así entendida, en la que todos los partícipes se sienten protagonistas, reclama: a) que se establezcan los cauces, medios e instrumentos para que efectivamente sea viable e, igualmente, su revisión, actualización y mejora progresiva; b) que, en ningún caso, se entienda como que todos, en todo y en todo momento, han de ser informados, consultados, decidir y controlar, sino que, la racionalidad y el sentido común, aconsejan que sólo sean objeto de consideración aquéllas cuestiones, problemas, planes y proyectos que, por su relevancia, afectan a todo el conjunto o una gran parte de éste e implican modificaciones más o menos sustanciales respecto de situaciones anteriores, pues incu- 
rrir en una excesiva pormenorización resultaría ineficaz y hasta ralentizador de los procesos que tienen su propio ritmo y dinamismo.

Si se quiere, realmente, avanzar en prácticas democráticas y democratizadoras, es de suma importancia asumir sin claudicaciones y con todas sus consecuencias - a medio y largo plazo positivas- este sentido de la participación activa. "Tomar parte en", constituye algo así como lo más entitativo de la democracia. Debiendo añadir, además, que de nada serviría lo dicho si la democracia no va acompañada de una demopedia (educación) en la línea de acción-reflexión-modificación-acción, o, lo que es igual simultanear principios teóricos y praxis fundamentada en los mismos, introduciendo los ajustes a que haya lugar. Tal modo de entender democráticamente la educación, va muchos más allá del "to learn learning", ya que la persona se convierte en sujeto activo en su doble dimensión individual y colectiva. $\mathrm{Y}$ el resultado es una sociedad más humana y más humanizante.

De la representatividad al "liderazgo tecnocrático" pasando por la "partitocracia representacionista".

Con lo dicho hasta este momento, ya tenemos elementos de juicio suficientes para realizar una crítica radical a las democracias occidentales que, al parecer, se nos presentan como la expresión más acabada —y hasta última - del insuperable modelo democrático liberal, defendido y sustentado a ultranza por Estados de Derecho Liberal sobradamente conocidos. Apoyados, incluso, por equipos de analistas y teóricos que, a la manera de "caballos con orejeras", sólo miran en una dirección, porque, en última instancia, para éso se les contrata y se les paga. Sirven servilmente a determinados grupos de poder y de intereses, haciendo caso omiso de inmensas mayorías que, por carecer de "voto de mercado" son consideradas como "demanda insolvente" y el único "horizonte de esperanza" que les queda, es el de morir en su pobreza extrema, miseria e indigencia. Es la lógica del sistema soçioeconómico dominante, apto para ganadores que no se preguntan por las causas y consecuencias de su triunfo.

La democracia liberal que, con matices relativamente diferen- 
ciadores, se ha extendido por el mundo llamado occidental y algunos otros países, se define a sí misma, como democracia representativa, porque a sus parlamentos, congresos, cámaras o asambleas, acceden por vía electoral los representantes que el pueblo elige para gobernar y para, desde el poder legislativo, ejercer un relativo control del poder ejecutivo. Celebrando elecciones con la periodicidad establecida, se abre la posibilidad de alternativas entre gobierno y oposición. Incluso, cuando se trata de problemas de gran transcendencia, se introduce otra posibilidad, la de realizar un referendum, de manera que toda la sociedad tenga la oportunidad de expresarse. Hasta aquí, poco o nada que objetar, siempre que admitamos que se trata de una democracia "bajo mínimos", o, como también se ha calificado como "de baja intensidad".

A nadie se le oculta que esta democracia liberal presenta, en su praxis, puntos débiles significativos que de ninguna manera pueden ni deben pasar inadvertidos, tales como: 1) Se ha hecho compatible con desigualdades económicas y sociales que, lejos de reducirse, se han ido acrecentando entre individuos, entre grupos y clases y entre países; 2) El poder, en su mayor parte, ha sido asumido por oligarquías plutocráticas fuertemente arraigadas, que lo controlan y manipulan en favor de sus propios intereses, y excluyen, por tanto, a la mayor parte de la sociedad, que les queda subordinada cuando no sometida; 3) Permiten, así, en la vida política real, la existencia de prácticas autoritarias -en ocasiones, evidentes dictaduras-, que antidemocráticamente ignoran a importantes colectivos sociales; 4) $\mathrm{Si}$, además, se ha accedido al poder por vía electoral, mediante control y hasta manipulación de las elecciones, el ejercicio del poder no tarda en aparecer como arbitrario y prepotente, relegando a los grupos opositores al papel de simple y pura comparsa, con la única concesión de que sean oídos pero no escuchados; 5) En los países desarrollados y en vías de desarrollo, se plantean problemas políticos, económicos y sociales, muy diferentes a los que han surgido en las etapas anteriores de la revolución industrial, de ahí que, éstos, no se puedan afrontar y menos resolver en el marco político diseñado para situaciones propias de los comienzos de la revolución industrial; porque, en el fondo, se parte del convencimiento de que son las élites de la sociedad las únicas capaces de descubrir e interpretar cuáles son los 
intereses del conjunto de los ciudadanos.

Los cuatro puntos señalados, me permiten afirmar que en el seno de las democracias liberales y en sus mismas raíces se registra un importante y creciente déficit democrático. Si a ésto añadimos, que los partidos políticos se han ido convirtiendo en auténticas "máquinas electorales", su práctica democrática queda aún más negativamente afectada. Acceder y mantenerse en el poder se constituye en objetivo prioritario. El contacto directo y explicativo con su propia militancia no se plantea con suficiente periodicidad y sus contenidos son a todas luces escasos desde el punto de vista ideológico, programático y analítico-crítico. Esta insuficiencia se convierte en carencia cuando se trata de simples votantes y adheridos. Así, de alguna forma, eluden rendir cuentas con cierta frecuencia y, en tanto elegidos, se alejan del posible y deseable control de sus electores. No desarrollan una pedagogía política activa y sus seguidores, salvo excepciones, quedan marginados hasta que, al plantearse nuevos comicios electorales, hay necesidad de apelar a su voto, en costosas y reiterativas campañas que, de informativas y consultivas tiene bien poco y, aún menos, para introducir una mínima participación en los niveles de decisión y de control.

Por estas razones, es por lo que se afirma que la democracia liberal-formal, en vez de avanzar hacia una democracia social-real, con proyección hacia la vida económica, social y cultural, se ha estancado en la "partitocracia" o gobierno elitista de los partidos. Esto, precisamente, quiere expresar el paso de una deseable representatividad a un rechazable "representacionismo" como expresión de falta de coherencia democrática. Dicho de otra forma, los líderes, los cuadros, una vez instalados en el poder caen en el "ombliguismo" y se alejan u olvidan de sus bases políticas y de los colectivos cuyos intereses, aspiraciones y expectativas representan la componente utópica de toda ideología política; de hecho, aunque en ocasiones se recuerde, lo es con poca convicción y, consiguientemente, pierde relevancia. En definitiva, se ha traicionado el proyecto político que se propugnaba y, de manera sutil se ha optado por el pragmatismo e inmediatismo que todo lo invade y que, unos más y otros menos, todos hemos interiorizado de alguna forma y en algún grado. 
Estos comportamientos que, siendo fieles al sentido radical y profundo de la democracia, no se pueden considerar democráticos, no se dan por casualidad. Tienen sus causas profundas: subjetivas y objetivas. Para no extender demasiado este trabajo, $-\mathrm{y}$ no por ser menos importantes-, no nos detenemos en las causa subjetivas de índole psicológica individual y colectiva. Sí repararemos en las causas objetivas. Veamos.

En lo que a interpretaciones sociológicas se refiere, todo es cuestionable y discutible. También lo que seguidamente expreso. Parece bastante plausible y cierto que la mayor parte del poder planetario se detenta por las grandes empresas multinacionalestransnacionales. Aproximadamente por unas seiscientas de ellas, que representan más o menos el diez por ciento de las existentes. Se trata de empresas que, por disponer de abundantes medios materiales y humanos dedicados a la investigación, se hallan en condiciones de producir altas tecnologías a buen ritmo y, asimismo, modernas técnicas organizativas y administrativas. Su poder deriva de la tendencia inherente a las mismas a concentrar la información procesada en sus élites ejecutivas, porque así toman las decisiones más importantes $\mathrm{y}$, además, disponen de los medios necesarios para controlar el proceso y, si es caso, corregir desviaciones y modificarlo si las circunstancias lo exigen. $Y$ todo ello, con el objetivo de: aumentar la producción y la productividad, reducir costos, mantener e incrementar sus cuotas de mercado, obtener más beneficios y asegurar la acumulación de capital necesaria para seguir ocupando la posición de líderes. Podríamos decir que la innovación tecnológica o la tecnologización, - sin dejar de reconocer lo mucho de positivo que ha aportado y seguirá aportando-, conduce al "liderazgo tecnocrático".

Su argumento, en general, se puede formular así: el pueblo, la clase trabajadora, los colectivos sociales y políticos organizados, la sociedad, no puede entender ni comprender la gran complejidad de los problemas propios de la era tecnológica en que nos encontramos. Tal comprensión, organización y dirección, es algo privativo de las élites ejecutivas depositarias del "saber tecnológico", porque poseen puntual y debidamente procesada la información que, así, se constituye en materia prima imprescindible para decidir y orientar las decisiones de la población. Mediatizando, si sus 
intereses lo exigen, el ejercicio del poder estatal en cada país, lo que confirma su carácter transnacional; o, lo que es igual, a sus efectos, las fronteras no existen, ni política ni económicamente.

Este modelo, es decir, - "élite tecnocrática"-, en cierto modo y medida, se ha trasladado a las cúpulas de los partidos políticos, de forma que éstas, actuando a la manera de "élites", aspiran a perpetuarse en el poder, dando lugar al profesionalismo político. Y, si por añadidura, se trata de líderes políticos carismáticos, entonces, su permanencia, se halla asegurada por bastante tiempo, asentada en la incultura política popular. Las decisiones de los dirigentes políticos que, repetidamente, proclaman que responden a las necesidades de la sociedad, terminan siendo respuesta a intereses de grupos más o menos privilegiados. El pueblo sigue siendo el gran ausente. Tal percepción, viene confirmada por la desconfianza, el desaliento, la indiferencia y los altos índices de abstención que se observan en las elecciones, sea cual fuere el objetivo de éstas. Por este camino, que es el que seguimos en el mundo occidental "democrático", el pueblo no sólo no madura políticamente, sino que no llegará a madurar nunca, ya que la política es cosa de "profesionales" y de "especialistas", haciéndose verdad éso de...."todo para el pueblo, pero sin el pueblo". El pueblo sigue inmerso en una especie de círculo fatal del que no puede salir. ¿Se habrá perdido toda esperanza, o, por el contrario, podrá ésta recuperarse $y$, contra viento y marea, tendremos que seguir luchando por un modelo de sociedad democráticamente más tolerable?

\section{Dificultad adicional: el sistema capitalista desnaturaliza y per- vierte la democracia.}

El capitalismo liberal ha engendrado, con la fuerte presión y complicidad de la burguesía comercial, industrial y financiera, la que seguimos denominando democracia liberal. Respecto de la situación absolutista y postfeudal, la democracia liberal innegablemente representó un importante avance para la sociedad, pero la distancia a recorrer para llegar a una democracia real y social es muy larga. Hay que expresarla en décadas, para no alimentar falsas ilusiones. Pero el esfuerzo, viene realizándose también desde hace décadas. No es de hoy ni de mañana. 
El individualismo utilitarista que, - no nos vamos a engañar-, anida en todos y cada uno de nosotros, como actitud motriz del liberalismo económico (capitalismo), genera, a su vez, actitudes y conductas insolidarias $y$, por ende, no democráticas. Cosa que, por otra parte, no se supera con gestos altruístas y voluntaristas, y menos en tertulias con café y con pastas. ¿Por qué? Sencillamente, porque en el origen de las sociedades occidentales eurocéntricas, lo que realmente predomina es la voluntad de construir una sociedad puramente económica. Su racionalidad economicista, que no económica en rigor, ofrece un paraíso de abundancia y felicidad, ... pero, ¿para cuántos? y ¿para quiénes?. La respuesta a estas interrogantes la dejo en manos del lector.

De Max Weber, sustentador teórico -económico, político, social e ideológico - del capitalismo moderno es esta frase: "la economía llega a autonomizarse e independizarse de otras realidades humano sociales, e impone su racionalidad a todas ellas". Y también esta otra: esta autonomía económica es "la brecha por la que la sociedad occidental ha asumido el espíritu del capitalismo". No hace falta ser muy lúcido y sagaz para deducir que las enormes desigualdades que hoy percibimos y constantemente son objeto de denuncia, son la consecuencia. Nuevamente, insisto, quienes desde posiciones interesadas y con argumentos pseudointelectuales se constituyen tercamente en defensores del liberalismo económico y político, tienen la obligación moral de realizar una crítica rigurosa y seria, al tiempo que, intelectualmente, se someten a una razonable autocrítica. De no hacerlo, podrán incurrir hasta en una perversión intelectual al servicio de quienes más tienen y en detrimento de quienes sólo poseen insuficiencia, miseria y desesperanza. Seguirán favoreciendo a los privilegiados y opulentos y perjudicando a los pobres y oprimidos de la tierra. Es mucha la responsabilidad social como para no repensar sus actitudes y planteamientos.

Una manipulación inaceptable: oposición entre mercado y Estado.

Desde hace ya varios años y desde posiciones "neoliberales", -para quien este trabajo suscribe "veteroliberales" —, como consecuencia, entre otras, de la estrepitosa caída del llamado "socia- 
lismo real", se repite insistentemente la antimonía (de hecho incompatibilidad) entre una "economía de libre mercado" y una intervención del Estado en la vida económica, por considerar que dicha intervención, en última instancia, resulta nociva para el libre desenvolvimiento de la actividad económica que, según los clásicos mas clásicos, debe quedar en manos de la iniciativa privada e individual. En actitud cuasi enfermiza, amparándose en el indiscutible fracaso de la planificación estatalista, impuesta e imperativa, niegan la posibilidad a toda planificación, aunque ésta se halle inspirada en principios sociales y democráticos. La planificación, "per se", sostienen, nunca puede ni podría ser democrática. Hay, según se dice, una oposición entre mercado (sociedad) y Estado. Subrayan tres incongruencias (mitos), entre las funciones del sector público y del sector privado, a saber:

- El sector público es demasiado grande, particularmente en los países en desarrollo. Pero ni se plantean, de manera real, razonable y solidaria, quién o quiénes, cuándo, cómo y con qué medios se debe dar respuesta a las necesidades colectivas y sociales.

- Con la privatización máxima cambiará, dicen, el equilibrio entre los sectores público y privado que es tanto como decir que las leyes de mercado, funcionando con libertad, es decir, reduciendo a la condición de mercancías que se compran y se venden los servicios (sanidad, medicina, enseñanza, educación), serán mejor prestados y atendidos. No está demostrado, desde la lógica del bien común -el de todos-, que el sector privado sea garantía de equilibrio y mejor servicio. Sólo es así, si se trata de los sectores con alto nivel de ingresos, es decir, los más acomodados.

- La actividad del Estado debe ser mínima, no realizando las tareas que puedan efectuar los particulares con eficacia y eficiencia. Pregunto, ies el caso de las necesidades anteriormente citadas?, ¿es que las necesidades colectivas y sociales - bien común - van a ser mejor atendidas para todos por el hecho de que se traduzcan a categorías mercantiles inspiradas en el beneficio privado?

Desde el derrumbe del "socialismo" soviético y de los países de 
su órbita, amparándose en la ineficacia e ineficiencia de una planificación estatal exageradamente burocratizada, con muy escaso o nulo rigor, se manipula de modo inaceptable la oposición entre "economía de libre mercado" y "Estado interventor en exceso". Habría que analizar caso por caso, país por país, para ver en qué medida es verificable este aserto. Más cierto es que la "economía de libre mercado" sólo ha existido en los libros de texto como lo afirman reconocidos autores, nada sospechosos, porque se enmarcan en el ala liberal. Lo que pasa es que no son bien vistos por su actitud crítica ante las incongruencias del "veteroliberalismo" disfrazado de "neoliberalismo". Es muy dudoso, asimismo, que hoy, tras la práctica desaparición del marxismo-leninismo (comunismo), se pueda hablar de "Estados en exceso interventores" porque recaban recursos de la economía para atender necesidades colectivas. $Y$ conste, que ésto no supone valorar positivamente el exceso de burocracia y no pocos casos de ineficacia e ineficiencia, que lo que sí demandan es un control riguroso y bien planteado. A una planificación del sector público, técnicamente bien planteada y político-socialmente bien controlada, es decir, a una planificación democrática y social, no hay por qué negarle el pan y la sal, entre otras razones porque aún no se ha dado y sería el paso necesario para que una democracia liberal se vaya transformando en democracia real y social.

El proceso lógico hacia una democracia real, representativa y social, es el que encuentra férrea resistencia y oposición en el "veteroliberalismo". Tal vez no nos equivoquemos, si decimos que el problema de fondo es que el mercado y el Estado están dominados por las mismas estructuras de poder (dinero-riqueza), que sienten verdadero pánico para aceptar el control de la sociedad. ¿Por qué? Porque ese control social y democrático modificaría la estructura social y, a no muy largo plazo, quienes hoy detentan el poder por procedimientos dudosamente democráticos, se verían afectados y sus intereses comprometidos. Lo importante, pues, es conservar la actual estructura socioeconómica y no pretender, en aras del bien común o bienestar general, controlar razonable y eficazmente el mercado y el Estado. No importa que tal oposición sea ocasión de actitudes y conductas autoritarias - dictaduras encubiertas-, ya que lo importante es mantener, a costa de mucha hambre y mucha muerte en el mun- 
do, la ficción de una "economía de libre mercado" que nunca ha existido. Decir esto, no supone negar la incuestionable realidad y necesidad del mercado, sino en el marco de una auténtica racionalidad económica, ponerlo en su sitio. De no ser así, el caos y el desastre seguirán siendo una constante histórica. No van descaminados quienes opinan que, una nueva forma de fascismo, es aquélla que sigue autodenominándose democrática al tiempo que mantiene dividida la sociedad en clases sociales con intereses contrapuestos $y$, en consecuencia, a las personas interiormente escindidas y en situación insolidaria.

\section{La revolución pendiente o una puerta a la esperanza: recuperar la sociedad civil por medio de una democracia participativa.}

En el modelo de sociedad occidental en que vivimos, la democracia liberal sigue considerando al ser humano más como "homo economicus" que como persona, que, al tiempo que mantiene su subjetividad individual, tiene una dimensión social y comunitaria. La persona o crece en solidaridad o no se desarrolla como persona. Consecuentemente, la democracia, sin hacer de ella un absoluto, se nos muestra como un medio válido al servicio del hombre en su totalidad, es decir, individual y en relación solidaria con los demás hombres. Esta afirmación supone reconocer la dignidad absoluta de toda persona.

Así, la convivencia social y solidaria, se convierte en valor referencial de primera magnitud, porque permite orientar la acción política tratando de armonizar los intereses de individuos, grupos, sociedades y países, siempre que se construya con respeto a la dignidad y libertad de todos y cada uno de los seres humanos. Y, así, como no podía ser de otro modo, la democracia social y participativa se convierte en exigencia ética que, a su vez, genera una forma de vivir más humana, lejos del "homo economicus" propio de las democracias liberales. Para orientar los pasos de modo coherente con esta exigencia ética, no queda más remedio que revisar.crítica y autocríticamente el actual modelo de desarrollo neoliberal e insolidario, al tiempo que plantear serias interrogantes al estilo de vida predominante en el mundo occidental. La "cultura de la riqueza" y la "civilización de la abundancia y opulencia", consecuencia de la acumulación privada de capital, 
- sea en individuos, grupos, transnacionales, número reducido de Estados-, convencidos de que así se puede llegar a un desarrollo económico-social-cultural equilibrado, armónico y solidario, no pasa de ser retórica quimérica para manipular la opinión pública y engañar a incautos.

La democracia, para ser real y participativa, no puede reducirse a ejercer el derecho de voto que, como queda claramente dicho, transforma la democracia en "tecnocracia", de forma que las "élites elegidas" o "tecnocráticamente impuestas", se constituyen en únicos intérpretes de la voluntad popular, haciendo uso manipulador y abusivo de los medios de comunicación social. El individuo, la persona, el ser humano, para serlo de verdad, no puede ni debe abandonar su derecho-obligación-responsabilidad de decidir, en manos de ningún poder, sea público o privado, porque ello sería tanto como renunciar a su libertad y autonomía relativas.

La democracia participativa entiende y asume la participación como "tomar parte en" y en tal sentido reclama: -información suficiente, inteligible y oportuna; -mecanismos o cauces de consulta respecto de planteamientos y opciones que incumben a los ciudadanos; - tener voz propia para decidir en solidaridad con los demás sobre problemas de envergadura y trascendencia; - y disponer de instrumentos para verdaderamente controlar la actividad de quienes gobiernan y dirigen el proceso político y económico, para cuya misión fueran temporalmente elegidos.

En la actualidad las organizaciones sociales y ciudadanas (sindicatos, movimientos pacifistas, ecologistas, feministas, indígenas y otros que prestan servicios sociales y culturales de ámbito nacional e internacional), representan, con su propia estructura democrática, a una parte importante de la sociedad civil, y, en cierta medida, también son nexo o eslabón entre lo político (Estado) y lo público (Sociedad civil). Su experiencia, con sus errores y aciertos, constituye una fuerza social y política, que de ningún modo puede ignorar una democracia participativa. Los partidos políticos deben arbitrar mecanismos y medios para mantener una relación continuada y constructiva con estos importantes movimientos sociales y ciudadanos, evitando caer en la tentación de manipularlos e instrumentalizarlos al servicio de sus programas e ideologías. Si así actuasen pondrían de manifiesto su carácter 
antidemocrático. La relación, si llega a establecerse, debe de ser desde la autonomía y la independencia, con un objetivo común: construir y potenciar simultáneamente la sociedad civil y la democracia participativa. No hay fórmulas, ni la empresa es nada fácil. Sólo hace falta no cejar en el intento con imaginación, creatividad, actitud de servicio y profundo espíritu democrático, conscientes de que así se construye un futuro más humano para las nuevas generaciones. De esta forma, podemos afirmar que la democracia participativa es la alternativa de futuro a la democracia neoliberal que, en términos de solidaridad, representa el pasado y la decadencia. Es el momento, también, para empezar a recuperar utopía y subrayar que el liberalismo no representa el fin de las ideologías y que afirmar que el hombre liberal es el "último hombre" no pasa de ser una monumental estupidez.

\section{La Democracia participativa exige, simultáneamente, interacción éonómica, política y ética.}

El neoliberalismo actual -leáse economicismo-, con frecuencia ignora y hasta niega la dimensión ética de la vida humana. Es radicalmente materialista y por ello dicho aspecto le pasa desapercibido. De vez en cuando, para no quedar tan mal, recurre a una retórica pseudoética que no pasa de ser simple verbalismo. Sus efectos inhumanos son clamorosos: individualismo creciente, desigualdades persistentes y en aumento e insolidaridad en todos los niveles. En el fondo, cae en la perversión de subordinar la política y la ética a la economía entendida a su manera, considerándola como variable independiente y así la perspectiva social y comunitaria se percibe como algo difuso e impreciso.

A quienes siguen pensando y actuando en clave neoliberal, les resulta muy difícil salir de la lógica economicista y entrar en una lógica integradora y solidaria, ya que para ello han de supeditar la libertad económica a la libertad política y a las exigencias que se derivan de la ética, lo que no supone negar la economía sino hacerla más humana. Hacer entender ésto a un neoliberal convencido y militante es tarea ardua pero no imposible.

Debo aclarar, que cuando me refiero a la dimensión ética, no me refiero a la "ética en los negocios" concretada en "códigos nor- 
mativos", sino a una ética más profunda, de convicciones, de mentalidad, de actitudes interiores críticas y de comportamientos comprometidos consecuentes, que apuesta por defender parcelas de libertad y de autonomía en la persona para pensar por sí misma y autocriticarse, eludiendo hasta el límite de lo humanamente posible la sumisión y sometimiento a cualquier tipo de institución y de ideología creada por hombres, sea ésta económica, política, social, cultural o religiosa, convencido de que todo es transformable y perfectible en orden a avanzar en una línea de humanización. Esto equivale a asumir la ética $-y$, en mi caso concreto, también la fe cristiana-, como instancias radicalmente críticas.

De esta forma, además, recuperamos utopía en el sentido siguiente: - distribución razonable, justa y equitativa de los bienes de la tierra (materiales, culturales y espirituales), considerando que lo que a unos pocos les sobra a unos muchos les falta; - aceptar que el beneficio es un valor (aunque no todo beneficio lo sea), pero no sólo el individual sino también el colectivo; - afirmando que el hombre, la persona, sea libre para pensar, juzgar y actuar, siempre que reconozca que la libertad de los demás es condición necesaria para su propia libertad;

- insistiendo en que la democracia participativa es una aspiración individual y colectiva como expresión de la verdadera democracia que siempre se estará construyendo por ser un proceso inacabado; - presionando para que se concrete en un proyecto económico-político-social-cultural superador de la insolidaridad e impulsor de la solidaridad; - exigiendo que critique el consumismo en su radicalidad y haga posible una austeridad compartida y solidaria como expresión del bien común; - contribuyendo a que el diálogo y el consenso, abandonando posturas irreductibles, logre descubrir el carácter de los conflictos racional y razonablemente planteados, lo que no debe confundirse con la eliminación de conflictos; - propugnando que se rechace la imposición inherente a la lógica ciega del mercado y de la racionalidad tecnológica; - proponiendo que se renuncie al poder como medio de defensa de intereses de grupo o de medro personal y se ejerza como servicio a la sociedad.

Asumiendo este proceso, y de acuerdo con Durkheim, "la democracia es la forma política por la que la sociedad llega a la 
conciencia más plena de sí misma; un pueblo es tanto más democrático cuando la deliberación, la reflexión, el espíritu crítico, desempeñan un papel más considerable en la marcha de los asuntos públicos. Es tanto menos democrático cuando el inconsciente, los hábitos no conocidos, los sentimientos oscuros, son más preponderantes". Chesterton expresaba algo que todo político debe interiorizar y nunca olvidar,... "que las cosas comunes a todos los hombres son más importantes que las privativas de cada uno o cada grupo en particular".

\section{Pero, ... la terca y dura realidad nos recuerda que está ahí.}

La realidad mundial, objetivamente, nos permite descubrir hechos, fenómenos y situaciones, que particularmente y más todavía en su conjunto, representan un serio obstáculo para avanzar hacia una democracia social, representativa y participativa. ¡Y qué casualidad!, todos los hechos que constatamos y citamos a continuación se producen bajo la égida y auspicios de un capitalismo neoliberal al que, en número nada. desdeñable, rinden culto $y$ pleitesía líderes políticos y económicos en prácticamente todo los países. ¿Serán ciertos o fruto de una observación retorcida y masoquista por mi parte?. El juicio queda en manos del buen criterio del lector.

Sin atribuir prioridad a los hechos de acuerdo al orden en que se citan, a vuela pluma destacaré los siguientes:

- El progreso técnico-económico en las distintas áreas-geográficas, no coincide con el progreso cultural-integral realmente humano.

- No se distingue entre nivel de vida (expresado en categorías consumistas) y calidad de vida (de orden cualitativo, conducente a la realización personal).

- Al tiempo que, enfáticamente, se opta por el progreso, considerando que éste ha de posibilitar servicios públicos que aumenten la calidad de vida para todos, se minusvalora y menosprecia en principio el sector público.

- Se reitera el derrumbe del "socialismo real" a causa, entre otras, de su excesiva "tecnocracia" y "burocracia", sin caer en la cuen- 
ta de que, con matices diferenciadores y por vía privatizadora, se incurre en los mismos defectos, generando altos niveles de corrupción.

- El neoliberalismo muestra una clara hostilidad hacia los sindicatos cuando oponen resistencia a su domesticación, incurriendo así en prácticas decimonónicas y, ello, a pesar de que la gran empresa multinacional-transnacional, en ocasiones, llega a instrumentalizar a algunas organizaciones obreras.

- Se insiste, y con razón, en denunciar e investigar los casos de corrupción en la vida pública, pero no se pone el mismo empeño cuando los casos se registran en la vida privada.

- Con frecuencia se subraya la importancia de revitalizar la cultura cívica y democrática, pero el exceso de pragmatismo que se puede observar, entraña una gran dificultad para desarrollar verdaderas capacidades y actitudes críticas, con lo que se frena el deseable avance hacia una democracia real y participativa.

- No se afrontan con decisión problemas graves como:

* el creciente desempleo que se registra a nivel mundial.

* la violencia en sus múltiples formas.

* los efectos demoledores de la alienación consumista.

* la intolerable discriminación femenina, racista y de culturas indígenas.

* la infravaloración de la identidades culturales, a causa del impacto homogeinizador de las sociedades tecnologizadas y consumistas.

* las dificultades que se oponen para que puedan emerger las "fuerzas de cambio" que, a la manera de "sujeto histórico", puedan ejercer la presión necesaria para promover reformas que supongan alteraciones en la estructura social.

* la frustración y decepción que las grandes masas populares e incluso las más acomodadas, muestran ante la vida política tal y como ésta se desarrolla.

* la práctica desaparición de valores éticos o la mixtificación de los mismos, privando así a la sociedad de abrir caminos 
hacia una utopía crítico-constructiva.

* el hecho mismo de la llamada "postmodernidad" como fenómeno europeo-norteamericano, que tiende a ignorar no sólo al eufemísticamente llamado tercer mundo, sino también al cuarto mundo marginal que crece dentro de sus fronteras.

* salvo excepciones, que merecen ser destacadas, se crean muy pocos espacios de libertad, en los que el pueblo se exprese desde su propia realidad y se convierta en interlocutor válido.

* la cultura de la insolidaridad, de la confrontación y de la violencia se halla mucho más desarrollada que la cultura del diálogo, de la tolerancia, de la reconciliación y de la paz.

No se trata de enunciar problemas "ad infinitum", sino de dejar constancia de realidades objetivamente ciertas, sabiendo que todas ellas reclaman un análisis exhaustivo y matizado, y, que, en su conjunto, permiten ver con claridad que el mundo occidental inspirado en el mal llamado neoliberalismo se aleja mucho de ofrecer, no el mejor, sino el menos malo de los modelos de sociedad posibles. Sé, también, que el análisis resulta muy poco alentador, pero la honestidad y la coherencia personal, exigen expresar lo que ciertamente se observa, sin concluir, por supuesto, en que todo lo que se observa es absolutamente negativo y perverso. Sería una incorrecta interpretación.

La esperanza en un cambio que suponga transformación a medio y largo plazo de la injusta estratificación social, se fundamenta en los movimientos sociales a que antes me he referido, en el desarrollo de la participación activa y en la posibilidad de avanzar hacia una democracia participativa, aunque no sea con la celeridad deseada. La existencia de grupos de intelectuales, críticos y autocríticos, cuyos análisis se sitúan en el plano estructural, también son motivo de esperanza. Las insistentes llamadas a la solidaridad desde distintos ángulos, suponen igualmente un apoyo en la línea señalada. E, igualmente, por qué no, en el llamado mundo neoliberal, surgen y seguirán surgiendo voces que, por razones éticas, forzosamente han de someter a rigurosa crítica el modelo social que se construye desde sus presupuestos ideológicos. Afortunadamente, en el mundo creyente también existe un poten- 
cial de grupos que, por asumir su fe como compromiso con la vida, con toda la vida y con la vida de las personas concretas como valor absoluto, indudablemente serán fermento animador de un modelo de sociedad hecho a la medida del ser humano.

Hay, por tanto, caminos para recorrer por parte de quienes, pese a todas las dificultades, opten por ser inasequibles al desaliento. La capacidad de esfuerzo y de lucha seria, ética y razonablemente planteada no se puede considerar agotada. Las posibilidades del ser humano de hacer el bien y de hacer las cosas mejor, más allá del orden neoliberal, siguen existiendo. Es el momento de aprovisionarnos de paciencia histórica, que también es un componente de mi esperanza, de nuestra esperanza. Lo importante es que la sociedad mundial emprenda un camino nuevo y diferente respecto del que actualmente sigue. Los organismos internacionales deben hacer escuchar su voz en este sentido, de lo contrario incurrirían en una lamentable omisión. 